\title{
Prudent Practices for Personal Programming
}

Larry R. Falvello

University of Zaragoza - CSIC, Department of Inorganic Chemistry and Aragón Materials Science Institute, Pedro Cerbuna 12, 50009 Zaragoza, Spain

When engaging in the once-widely-practiced crystallographic tradition of writing computer programs for oneself or ones own research group only, although it may be possible to dispense with the clarity and definition needed for distributable software, it is still useful to maintain standards to ensure the veracity of the results obtained and the integrity of the software. Based on experience with programs involving diffractometer geometry, absorption corrections, and displacement-related calculations, practices are described which have the aims of assuring the accuracy of the results and of maximizing code reutilization. A brief discussion of programming languages and general strategies for local software development is also included, with special attention to the important point of not attempting to reproduce functions that are already done well by readily available software from other sources.

falvello@unizar.es

www.chemcrystal.org 